\title{
Influence of climate change on IDF curves for the metropolitan area of Barcelona (Spain)
}

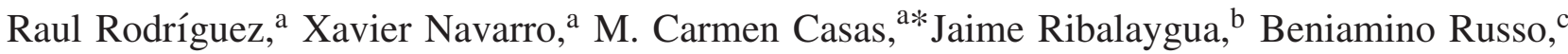 \\ Laurent Pouget ${ }^{\mathrm{d}}$ and Angel Redaño ${ }^{\mathrm{e}}$ \\ a Departament de Física i Enginyeria Nuclear (FEN), EPSEVG, Universitat Politècnica de Catalunya·BarcelonaTech (UPC), Vilanova i la \\ Geltrú, Spain \\ b Fundación para la Investigación del Clima, Madrid, Spain \\ c Clavegueram de Barcelona S.A. (CLABSA), Barcelona, Spain \\ d CETaqua Water Technology Center, Barcelona, Spain \\ e Departament d'Astronomia i Meteorologia (DAM), Facultat de Física, Universitat de Barcelona (UB), Barcelona, Spain
}

\begin{abstract}
The evaluation of the possible climate change influence on extreme precipitation is very interesting in the Mediterranean area due to the usual and characteristic high intensities of its rainfall pattern. This analysis is also very important in urban zones, especially those densely populated with complex sewer systems, generally vulnerable to torrential rainfall. In this work, a total of 114 simulated daily rainfall series, 84 for the period 2000-2099 and 30 for the control period 1951-1999, have been analysed. These series were obtained for six thermo-pluviometric stations located in the metropolitan area of Barcelona using the information provided by five general circulation models under four future climate scenarios of greenhouse gas emissions and applying statistical downscaling methods. The potential changes in the intensity-duration-frequency relationships due to climate change have been investigated. For the last third of the 21 st century, under A1B, A2 and B2 climate scenarios, an increase of at least $4 \%$ has been found on the expected daily rainfall with return period longer than 20 years. Using a temporal downscaling based on scaling properties of rainfall, future hourly extreme rainfall has been estimated. For almost all the scenarios and periods considered, the increase on the expected hourly rainfall has resulted slightly higher than the corresponding daily rainfall. The greatest differences between the future hourly and daily rainfall estimated have been found in the second third of the century under scenarios A1B (8\%) and A2 (9\%). Copyright @ 2013 Royal Meteorological Society
\end{abstract}

KEY WORDS extreme rainfall; climate change; IDF curves; temporal downscaling; scale analysis

Received 16 June 2012; Revised 3 March 2013; Accepted 30 March 2013

\section{Introduction}

The effects of climate change on hydrology and the potential intensification of the hydrological cycle have to be considered in order to prevent future problems in the urban drainage systems. The intensity-duration-frequency (IDF) curves, a very important tool used in the design and construction of different hydrological structures in water management, could be altered by a presumed increase of intense rainfall caused by climate change. A comprehensive view of the state of this concern was presented by Willems et al. (2011).

Contrary to mid- to upper latitude regions of the world in which an increase in total rainfall was reported, over the Mediterranean area several studies show a dominant decreasing trend during the last decades (IPCC, 2007).

\footnotetext{
* Correspondence to: M. C. Casas, Departament de Física i Enginyeria Nuclear (FEN), EPSEVG, Universitat Politècnica de Catalunya-BarcelonaTech (UPC), Campus Vilanova i la Geltrú - Edif. VG2, Avda. Víctor Balaguer, s/n, 08800 Vilanova i la Geltrú, Spain. E-mail: m.carmen.casas@upc.edu
}

Thus, the report assessing Regional Climate Change prepared by researchers from the CLIVAR-Spain network (Pérez and Boscolo, 2010) concludes that annual precipitation in the Iberian Peninsula in the last three decades has decreased significantly compared to the 1960s and 1970s, with the most important decrease observed at the end of winter. In spite of this decrease in total precipitation, an increase of extreme rainfall has been observed. Simulations for the 21 st century using climate models forecast also important decreases in total precipitation in the Mediterranean area, and in the Iberian Peninsula in particular, whereas some results from regional model projections show possible increases in torrential rainfall (Christensen and Christensen, 2003), with shorter and more intense episodes of precipitation. For the north-western Mediterranean region, Hertig and Jacobeit (2008) found an increase in precipitation in winter for the period 2071-2100 under scenario B2, while precipitation decreases in autumn and spring. An increase in anti-cyclonic conditions in the transition seasons (autumn and spring) in the Mediterranean region seems to be the cause of this reduction in precipitation. The increase in 
precipitation in winter would be due to an increase in the cyclonic conditions, particularly in December and January.

Buonomo et al. (2007) found that changes in extreme rainfall values become greater as both the return period of the rainfall becomes longer and the duration that is considered becomes shorter. Thus, for the European region on average, $24-\mathrm{h}$ rainfall with a return period of 20 years increases by $18 \%$ by the end of the 21 st century, while for a return period of 2 years the average increase is only $13 \%$. The increases are less when durations of more than $24 \mathrm{~h}$ are considered. In general, an increase in extreme rainfall is observed which is opposed to a reduction in the average annual precipitation. This indicates a change in the climate in the future with a substantial reduction in episodes of light to moderate rainfall and an increase in episodes of intense rainfall. In terms of the climate change factor, Larsen et al. (2009) found values generally above one for hourly rainfall in Europe under the scenario A2 for the period 2071-2100. For Spain, the climate change factor calculated was around 1.2 for return periods between 5 years and 100 years.

The evaluation of the possible climate change influence on extreme rainfall intensities is very interesting in the Mediterranean area, especially in densely populated urban zones with complex sewer systems, generally vulnerable to torrential rainfall. In this work, simulated daily rainfall series for the period 2000-2099 have been obtained for six pluviometric stations located in the metropolitan area of Barcelona. Four climate change scenarios (B1, B2, A1B and A2) have been considered. Changes in the current IDF relationships in the region have been calculated for every climate scenario using two different temporal downscaling methods: the first one assumes that the relative variations between the present and the future rainfall are the same for any duration shorter than $24 \mathrm{~h}$, while the second one, which is based on the scaling properties of rainfall, estimates these variations depending on duration.

\section{Obtention of simulated daily rainfall series for the period 2000-2099}

Different downscaling techniques are commonly used to infer information at regional scale from climate output at large scale provided by the general circulation models (GCMs). In the statistical approach (Wilby et al. 2004; Imbert and Benestad, 2005) high-resolution predictands, as rainfall, are obtained by applying relationships identified in the observed climate between these predictands and large-scale predictors, as atmospheric geostrophic fluxes, to the GCM output.

Using a statistical downscaling technique, daily rainfall series for the period 2000-2099 have been simulated by the Fundación para la investigación del Clima (FIC, Foundation for Climate Research). The development of the statistical downscaling method and the selection of predictors are based on the conceptual framework

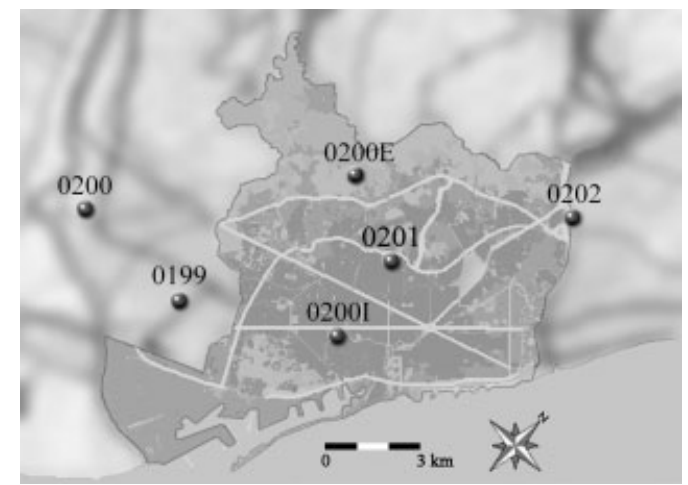

Figure 1. Thermo-pluviometric stations of the Spanish Meteorology Agency (AEMET) in the metropolitan area of Barcelona employed in this study. 0200E corresponds to the Fabra Observatory, where the Jardí gauge is located.

presented by Ribalaygua et al. (2013). The information provided by five GCMs, four from Fourth Assessment Report AR4 (EGMAM, CNCM3, ECHAM5 and BCM2) of the Intergovernmental Panel on Climate Change (IPCC, 2007) and one from Third Assessment Report AR3 (CGCM2) has been downscaled to generate simulated series corresponding to six thermo-pluviometric (TP) stations that belong to the Spanish Meteorology Agency (AEMET) installed in the metropolitan area of Barcelona (codes 0199, 0200, 0201, 0202, 0200E and 0200I in Figure 1). More than 20 years of observed daily rainfall data are available from these stations.

For verification of the methodology, data from the ERA-40 Reanalysis have been considered. The ERA-40 dataset cover the period from 1 September 1957 through 31 August 2002 at a resolution of $1.125^{\circ} \times 1125^{\circ}$ over the whole Earth's surface, four times daily (every $6 \mathrm{~h}$ ). However, this spatial and temporal high resolution should be relaxed to the GCM resolution (from $2^{\circ}$ to $3^{\circ}$ and generally daily data). The geographical limits of the atmospheric window used are $30^{\circ} \mathrm{N}$ to $55^{\circ} \mathrm{N}$ latitude and $27.5^{\circ} \mathrm{W}$ to $15^{\circ} \mathrm{E}$ longitude. This window covers the geographic area under study and the surrounding areas which have a meteorological influence. Different weights have been assigned to the grid points depending on their influence on the study area (Ribalaygua et al., 2013).

Three scenarios of greenhouse gas emissions, A1B, $\mathrm{A} 2$ and B1, and a control period from 1951 to 1999 have been considered for models EGMAM, CNCM3, ECHAM5 and BCM2. Two scenarios, A2 and B2, and a control period from 1961 to 1999 have been considered for model CGCM2 (IPCC, 2000).

The downscaling method used (Ribalaygua et al., 2013) estimates high-resolution surface meteorological fields for a day ' $x$ ' (the problem day), in two steps: the first step is an analogue technique (Zorita and von Storch, 1999), and in the second step high-resolution surface information is estimated for precipitation using a probabilistic approach. This procedure assumes that the relationships between predictors (large-scale atmospheric variables) and predictands (small-scale surface variables) 
will not vary in the future under climate change conditions. In the first step, like other analogue downscaling methods, for every day of the climate models outputs the most similar meteorological situations observed from past historical series are searched, using the atmospheric geostrophic fluxes as the relevant data for criteria of similarity. These fluxes determine the synoptic forcing that causes the air rises or descends, leading to cloud formation and precipitation. In addition, flow at $1000 \mathrm{hPa}$ provides information about the surface wind direction, which is very useful to study the effect of topography on the cloudiness and precipitation spatial distribution. Among the different algorithms which have traditionally been used to assess similarity between fields, the pseudo-Euclidean distances method (Kruizinga and Murphy, 1983; Martin et al., 1997) performed better. The similarity between the two days is calculated by determining (and standardizing) independently their likeness with respect to each of the four final predictor fields: the speed and direction of the geostrophic wind at 1000 and $500 \mathrm{hPa}$. The unlikeness of days $x_{i}$ and $x_{j}$, for each predictor field ' $P$ ', is calculated as a pseudo-Euclidean distance according to Equation (1):

$$
D_{p}\left(x_{i}, x_{j}\right)=\sqrt{\frac{\sum_{k=1}^{N}\left(P_{i k} P_{j k}\right)^{2} \cdot W_{k}}{\sum_{k=1}^{N} W_{k}}}
$$

where $P_{i k}$ is the value of the predictor ' $P$ ' of the day $x_{i}$, at the grid point $k ; W_{k}$ is the weighting coefficient of the $k$ grid point; and $N$ is the number of grid points of the atmospheric windows $\left(55^{\circ} \mathrm{N}-30^{\circ} \mathrm{N} ; 27.5^{\circ} \mathrm{W}-15^{\circ} \mathrm{E}\right)$ with resolution $\left(2.5^{\circ}\right.$ latitude $\times 2.5^{\circ}$ longitude $)$.

The calculated pseudodistances corresponding to every predictor have to be standardized before they can be combined to obtain a final measure of similarity. The standardization is carried out by substituting $D_{p}\left(x_{i}, x_{j}\right)$ by the dimensionless magnitude cent $_{P}$, which is the closest centile of the reference population of Euclidean distances among predictor fields ' $P$ ' to the $D_{p}\left(x_{i}, x_{j}\right)$ value. The centile values are previously determined, independently for each ' $P$ ' predictor field, over a reference population of more than 1000000 values of $D_{p}$. The reference population is calculated by applying Equation (1), with the same $W_{k}$ values, to randomly selected pairs of days. The final similarity measure, $\operatorname{sim}\left(x_{i}, x_{j}\right)$, between days $x_{i}$ and $x_{j}$ is given by the inverse of a weighted average of the $\operatorname{cent}_{\mathrm{P}}\left(x_{i}, x_{j}\right)$ for the four ' $P$ ' predictors (Equation (2)):

$$
\operatorname{sim}\left(x_{i}, x_{j}\right)=\left(\sum_{P=1}^{4} w_{P} \operatorname{cent}_{P}\left(x_{i}, x_{j}\right)\right)^{-1}
$$

where $w_{P}$ is the weighting coefficient of the predictor field ' $P$ '. Finally all predictors were considered equally important for the diagnosis of precipitation, so a value of $w_{P}=0.25$ was assigned for all of them.
The second step in the Ribalaygua et al . (2013) procedure is the determination of some relationships between large-scale atmospheric variables and the smaller-scale surface variables of interest, and its validation against observations. Future precipitation is estimated as the averaged precipitation observed for the most similar days found to each day to be downscaled. From the set of analogous days to the problem day ' $x_{i}$ ' found in the first step, a subset of the most similar $K$ is selected. Similarity in this second step is determined considering predictors related to precipitation, as moisture, flow convergence, thermal and moisture advection or stability. Every problem day $x_{i}$ has $K$ analogues $a_{j}$, each with a certain similarity $\operatorname{sim}\left(x_{i}, a_{j}\right)$ and an observed precipitation $\rho_{j}$. Then, precipitation $p_{i}$ for each problem day $x_{i}$ is estimated according to Equation (3).

$$
p_{i}=\frac{\sum_{j=1}^{K} \rho_{j} \operatorname{sim}\left(x_{i}, a_{j}\right)}{\sum_{j=1}^{K} \operatorname{sim}\left(x_{i}, a_{j}\right)}
$$

Verification of the downscaled climate model results under the present climate has been done calculating two errors: on the one hand the downscaled values of daily precipitation obtained from the European Reanalysis ERA40 data are compared to the observed data, and on the other hand the ERA40 data are compared to the simulated data obtained by regionalization of the GCM control period. The first error has been calculated to correct the biases introduced by the downscaling method, whereas the second one corrects the GCM results. Both errors have been calculated as the ratio between the two compared values for each day of the year and TP station and for 20 intensity quantiles, the upper quantile representing the heaviest precipitation. Multiplying both errors, the bias of the simulated daily precipitation series has been corrected for the control period (1951-1999). For the climate simulation period (2000-2099) the same bias correction has been considered, and every future day has been corrected using the factor calculated for the corresponding intensity quantile and day of the year. Compared to observations, the simulated series obtained after this verification process underestimate in general the expected rainfall amount for all seasons except in summer, where it tends to overestimate them. The greatest differences are observed in autumn. As known, due to their spatial and temporal resolution, the GCMs do not solve many short and small atmospheric structures and therefore do not properly simulate some atmospheric phenomena as the convective mechanisms. Thus, results are clearly worse at months with a significant fraction of convective precipitation in the region (autumn).

\section{Analysis of the daily rainfall series simulated for the period 2000-2099}

A total of 114 corrected and verified simulated series for the six TP stations have been obtained: 84 of these 
series correspond to the four future climate scenarios considered in the study (24 series for A1B and B1, 30 for $\mathrm{A} 2$ and 6 for B2), and the remaining 30 correspond to the control periods for the five general circulation models. The cumulative frequencies of the future daily rainfall series have been calculated for three 33-year periods, i.e. from 2000 to 2032, from 2033 to 2065 and from 2066 to 2099. Following the methodology described in Casas et al. (2004), their distribution tails have been fitted by the empirical potential-exponential function with three free parameters expressed by Equation (4),

$$
F(x)=1-m x^{n} \mathrm{e}^{-p x}
$$

where $x$ is the precipitation. Parameters $m, n$ and $p$ have been determined by the least-squares method for every series. Considering the fitted functions as cumulative frequency distribution functions of the daily rainfall, Equation (4) provides the $x$ value for each return period required, just introducing the corresponding cumulative frequency. Daily rainfall for return periods of $0.2,0.5$, 1, 2, 5, 10, 20, 50, 100, 200 and 500 years has been calculated for each of the 114 series mentioned above. To check the results, IDF relationships calculated for the control period have been compared to those based on historical rainfall observations (Willems and Vrac, 2011). Figure 2 shows the comparison between the historical intensity-frequency curve for $24 \mathrm{~h}$ obtained from the Jardí gauge located in the Fabra Observatory of Barcelona (1927-1991, 0200E in Figure 1) and the intensity-frequency points obtained from the climate models for the control period, averaged for the six TP stations, for return periods from 1 to 500 years. Differences have resulted lower than $10 \%$.

Expected daily rainfall for return periods from 0.2 to 500 years calculated for the 84 series corresponding to the six TP stations and the four future climate scenarios considered has resulted highly variable depending on the general circulation model used, as it has been previously referred (Ntegeka and Willems, 2008). Results for the six TP stations show some dispersion

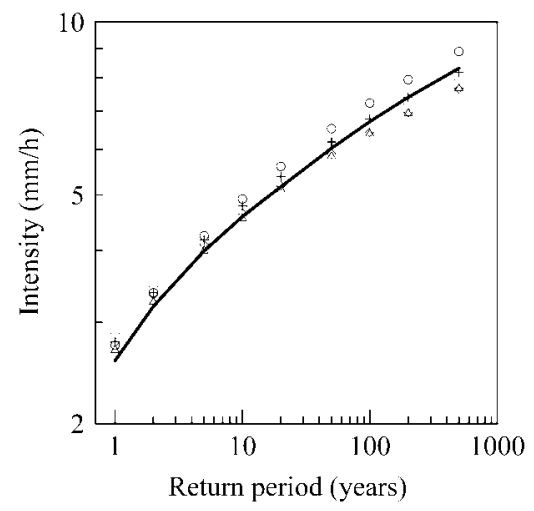

Figure 2. Current intensity-frequency curve for $24 \mathrm{~h}$ in Barcelona (continuous) compared to the intensity-frequency points obtained for the CGMs control periods considered: ECHAM5 (triangle), $\mathrm{CNCM} 3$ (circle), BCM2 (square), EGMAM (cross) and CGCM2 (diamond).

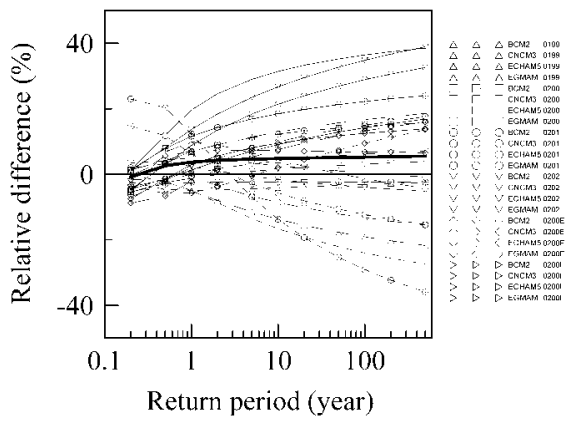

Figure 3. Relative difference between the expected daily rainfall with return periods from 0.2 to 500 years for the period 2066-2099 and for the control period calculated from 24 series ( 6 TP stations $\times 4$ CGMs) under climate scenario A1B.

also, despite their proximity comparing to the climate models resolution, indicating a strong dependence of the downscaling method with initial conditions. As an example, Figure 3 shows the relative difference between the expected daily rainfall for the period 2066-2099 and the control period calculated for 24 series corresponding to A1B scenario. For a return period of 1 year, variations from $6 \%$ decrease to $20 \%$ increase in daily rainfall intensities can be found, while for a return period of 10 years variations have resulted between $17 \%$ decrease and $31 \%$ increase. In spite of this dispersion it is possible to extract some first conclusion: it is remarkable that in most cases relative variations between the future and the corresponding control period daily rainfall are negative for return periods shorter than 1 year. This result is according to recent studies obtaining lower frequencies of the future low and moderate rain intensity values than those recorded in the last decades (Olsson et al ., 2009). Moreover, a clear tendency has been found towards increased extreme daily rainfall. Thus, for the second and the last third of the 21 st century and return periods longer than 50 years, daily rainfall increases for more than $60 \%$ of the cases: for the last third, increase is higher than $10 \%$ in more than $40 \%$ of the cases for scenarios A1B and $\mathrm{A} 2$, whereas for the second third increase is higher than $10 \%$ in $50 \%$ of the cases for A1B scenario.

The climate change factor $C_{f}$ (Arnbjerg-Nielsen, 2012) is defined as the ratio between the rainfall intensity with a return period $T$ and duration $d$ for a future climate scenario $\left(I(T, d)_{\text {Future }}\right)$ and the corresponding rainfall intensity in the present climate $\left(I(T, d)_{\text {Present in }}\right.$ Equation (5)).

$$
c_{f}=\frac{I(T, d)_{\text {Future }}}{I(T, d)_{\text {Present }}}
$$

From the simulated daily rainfall series (future climate) and those corresponding to the control period (present climate) climate change factors for each return period considered have been calculated using Equation (5). Table I shows these factors under the four climate change scenarios used, for the periods 2000-2032, 2033-2065 and 2066-2099. The climate change factors consigned in this table are the average values obtained for the different 
Table I. Climate change factors for the expected daily rainfall in the 21 st century with return periods from 1 to 500 years under the four climate change scenarios considered.

\begin{tabular}{|c|c|c|c|c|c|c|c|}
\hline \multirow{2}{*}{$\begin{array}{l}\text { 2000-2032 } \\
\text { Scenario }\end{array}$} & \multicolumn{7}{|c|}{ Return period (years) } \\
\hline & 1 & 5 & 10 & 20 & 50 & 100 & 500 \\
\hline A1B & 1.02 & 1.02 & 1.03 & 1.03 & 1.03 & 1.03 & 1.03 \\
\hline $\mathrm{A} 2$ & 1.00 & 0.99 & 0.98 & 0.98 & 0.98 & 0.98 & 0.97 \\
\hline B1 & 1.04 & 1.03 & 1.03 & 1.03 & 1.02 & 1.02 & 1.02 \\
\hline B2 & 0.99 & 1.02 & 1.02 & 1.03 & 1.04 & 1.04 & 1.05 \\
\hline \multicolumn{8}{|l|}{$2033-2065$} \\
\hline A1B & 1.00 & 1.03 & 1.04 & 1.05 & 1.06 & 1.06 & 1.08 \\
\hline A2 & 1.00 & 1.00 & 1.01 & 1.01 & 1.01 & 1.01 & 1.02 \\
\hline B1 & 1.01 & 1.02 & 1.02 & 1.03 & 1.03 & 1.04 & 1.05 \\
\hline B2 & 1.00 & 1.01 & 1.01 & 1.01 & 1.02 & 1.02 & 1.03 \\
\hline \multicolumn{8}{|l|}{ 2066-2099 } \\
\hline A1B & 1.04 & 1.05 & 1.05 & 1.05 & 1.05 & 1.05 & 1.06 \\
\hline A2 & 1.00 & 1.02 & 1.03 & 1.04 & 1.05 & 1.06 & 1.07 \\
\hline B1 & 0.99 & 1.00 & 1.00 & 1.00 & 1.00 & 1.01 & 1.01 \\
\hline B2 & 1.00 & 1.05 & 1.07 & 1.08 & 1.10 & 1.11 & 1.14 \\
\hline
\end{tabular}

CGMs and the six TP stations considered. Figures 4 and 5 show the factors corresponding to the second and last thirds of the century, together with their $68 \%$ and $95 \%$ confidence intervals. Extreme daily rainfall increases with a probability of $95 \%$ under scenarios A2 and B2 in the period 2066-2099. In almost all scenarios and periods the average climate factor has resulted higher as longer the return period is. The highest values (more than 1.1 for return periods longer than 50 years) have been obtained under scenario B2 in the last third of the century. However, results for scenario B2 could be less
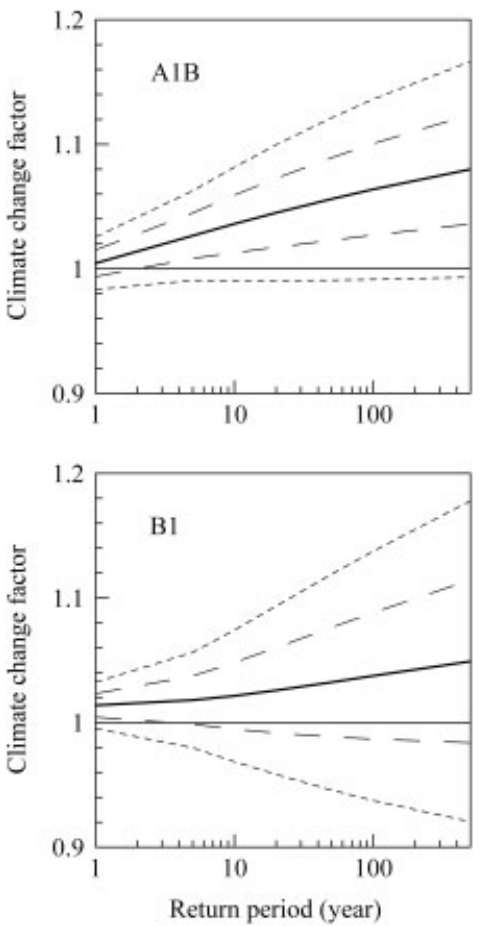

significant as those obtained for the rest since only one model contributes to B2 as opposed to the other scenarios for which four or five models have been considered. The last third is also the period in which the greatest increases have resulted under scenario A2, with slightly lower values (from 1.05 to 1.07 for return periods of between 50 and 500 years). The highest values obtained under scenarios A1B and B1 have been obtained in the second third of the century, with average climate factors between 1.03 and 1.08 for the same return periods. Only during the period 2000-2032 the average climate factor
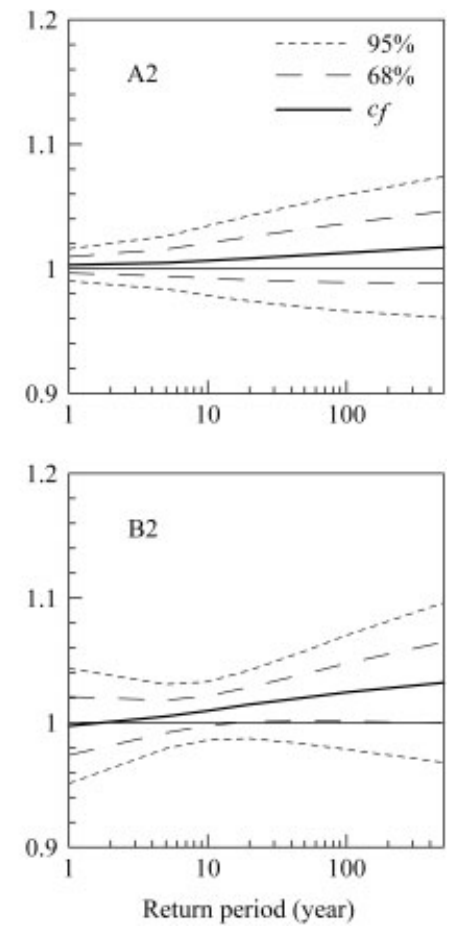

Figure 4. Average climate change factor (continuous) for daily rainfall, period 2033-2065 and scenarios A1B, A2, B1 and B2. The statistical uncertainty due to sampling variability is shown in the $68 \%$ and $95 \%$ confidence limits (dotted lines). 

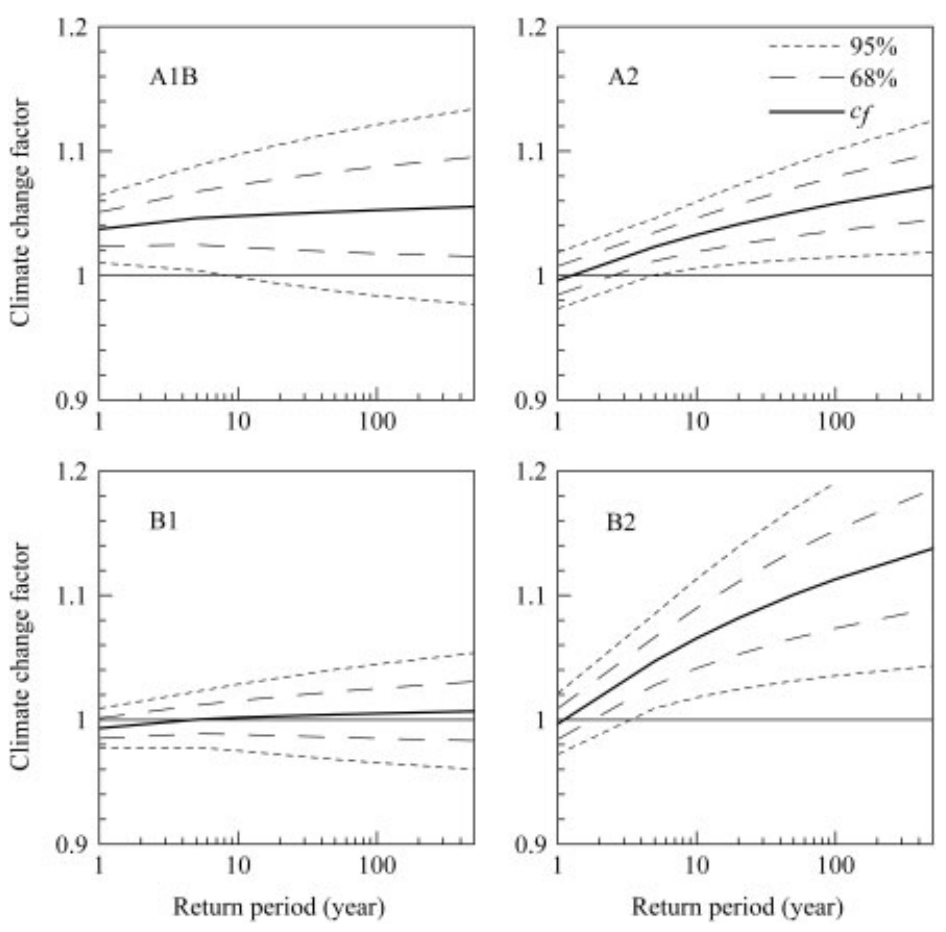

Figure 5. Average climate change factor (continuous) for daily rainfall, period 2066-2099 and scenarios A1B, A2, B1 and B2. The statistical uncertainty due to sampling variability is shown in the $68 \%$ and $95 \%$ confidence limits (dotted lines).

slightly decreases with increasing return periods: from 1.04 to 1.02 in the return period interval considered under scenario B1, and from 1 to 0.97 under scenario A2.

\section{Generating IDF curves for the different future climate scenarios in the metropolitan area of Barcelona}

In Section 3, the expected daily rainfall values for several return periods under the different climate scenarios considered were estimated for the area of Barcelona. To plot the intensity-duration-frequency curves from the daily rainfall values it is necessary to apply some temporal downscaling techniques or hypothesis to estimate rainfall intensities for durations shorter than 24 h, i.e. sub-daily durations. Here, we have tackled the problem using two different approaches.

\subsection{Invariance of climate change factors}

The straightforward approach to the problem consists of assuming that the relative variations between the present and future rainfall intensity is the same for any duration shorter than $24 \mathrm{~h}$. Assuming then that climate change factors are invariant with respect to the duration, the future rainfall intensities corresponding to any duration

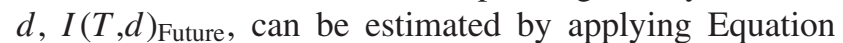
(5) where $I(T, d)_{\text {Present }}$ is determined using the updated generalized expression in Equation (6) of the current IDF curves for the city of Barcelona (Casas et al., 2004). Table II shows the $I(T, 1)$ Future values, which mean estimated intensities for a duration of $1 \mathrm{~h}$, for the same climatic scenarios and return periods considered in Table I.

$$
\operatorname{IDF}(T, d)=\frac{9.5 \log (T)+12.5}{(d+7)^{0.75}} 60 \quad[\mathrm{~mm} / \mathrm{h}]
$$

\subsection{Scaling invariance of rainfall}

An alternative temporal downscaling technique in order to estimate sub-daily extreme rainfall intensities from daily extreme rainfall intensities and generate future IDF curves is to use fractal properties of rainfall, i.e. scale invariance. The concepts of simple and multiple scaling to characterize the probabilistic structure of the precipitation process were introduced by Gupta and Waymire (1990). Burlando and Rosso (1996) demonstrated that a power law form of depth-duration-frequency can be derived theoretically from the scale invariance concept. Koutsoyiannis and Foufoula-Georgiu (1993) used a scaling model to predict storm hyetographs. Benjoudi et al. (1997) derived the equations of intensity-duration-frequency curves from the scale invariant relationship of multifractals. The scaling properties of maxima daily rainfall have been analysed in previous works. Menabde et al. (1999) developed a simple scaling methodology to use maxima daily rainfall statistics to infer the IDF curves for rainfall duration shorter than $1 \mathrm{~d}$. Nguyen et al. (2002) used temporal downscaling procedure to describe the relationships between daily extreme precipitations with sub-daily extreme precipitations using the scaling general extreme value probability distributions. Yu et al . (2004) developed regional IDF curves for non-recording sites based 
Table II. 1-h Rainfall intensity ( $\mathrm{mm} / \mathrm{h}$ ) for several return periods and climate scenarios, considering climate change factor invariant with duration.

\begin{tabular}{lccccccr}
\hline 2000-2032 & \multicolumn{7}{c}{ Return period (years) } \\
\cline { 2 - 8 } Scenario & 1 & 5 & 10 & 20 & 50 & 100 & 500 \\
\hline A1B & 33 & 50 & 58 & 65 & 75 & 83 & 101 \\
A2 & 32 & 48 & 55 & 62 & 72 & 79 & 95 \\
B1 & 33 & 51 & 58 & 65 & 75 & 82 & 99 \\
B2 & 32 & 50 & 58 & 66 & 76 & 84 & 103 \\
\hline $2033-2065$ & 32 & 50 & 58 & 67 & 77 & 86 & 106 \\
A1B & 32 & 49 & 57 & 64 & 74 & 82 & 99 \\
A2 & 32 & 50 & 58 & 65 & 76 & 84 & 103 \\
B1 & 32 & 49 & 57 & 65 & 75 & 83 & 101 \\
B2 & & & & & & & \\
\hline 2066-2099 & 33 & 51 & 59 & 67 & 77 & 85 & 103 \\
A1B & 32 & 50 & 58 & 66 & 77 & 86 & 105 \\
A2 & 32 & 49 & 56 & 64 & 74 & 81 & 98 \\
B1 & 32 & 51 & 60 & 69 & 81 & 90 & 111 \\
\hline
\end{tabular}

on the simple scaling theory combined with Gumbel distribution. Other authors who adopt the simple scaling methodology to derive IDF curves are Nhat et al . (2007), Desramaut (2008) and Bara et al. (2009).

The annual maximum intensity $I_{d_{0}}$ for a duration $d_{0}$ can be related to the corresponding intensity $I_{d}$ for another time scale $d$ by a factor that is a power function of the scale parameter $\lambda$, which is the ratio of the two scales $\left(d=\lambda d_{0}\right)$, considering Equation (7) as an equality between probability distribution functions.

$$
I_{d}=\lambda^{\beta} \quad I_{d_{0}}
$$

The scale invariance of the distributions results in the Equality as in Equation (8) of their moments of order $q$. If the scale function $K(q)$ is linear, $K(q)=\beta q$, the process is a simple scale process or monofractal. If not, the process is multiscalar or multifractal.

$$
\left\langle I_{d}^{q}\right\rangle=\lambda^{K(q)}\left\langle I_{d_{0}}^{q}\right\rangle
$$

From the scale properties analysis of the annual maximum daily rainfall series simulated for the period 2000-2099, the maximum rainfall intensities for subdaily durations higher than $1 \mathrm{~h}$ have been obtained. Previously, it is necessary to ensure that the durations from 1 to $24 \mathrm{~h}$ belong to the same scale regime. With this purpose, the scale analysis of the annual maximum rainfall series recorded by the Jardr gauge in the Fabra Observatory of Barcelona (Burgueño et al., 1994; Casas et al., 2004) has been done. Results show the same scale regime for durations between 1 and $30 \mathrm{~h}$. Figure 6(a) shows the statistical moments for different values of $q$ of the annual maximum intensity of the Jard $\tau$ series, with straight lines fitted to indicate scale invariance over the range from 1 to $30 \mathrm{~h}$. The slopes of these straight lines determine the scale function $K(q)$. Figure 6(b) shows the linear relationship found between $K(q)$ and the order $q$ of the statistical moments. Therefore, the simple scaling can be assumed for these series, with a scaling exponent $\beta$ that can be estimated from the slope of the linear regression. The slope value $(-0.781$ in Figure $6(b))$ is comparable to the exponent calculated for the power function that expresses the dependency on duration in the current IDF curves for Barcelona (Equation 6).

In an analogous way, the scale behaviour of the statistical moments of the annual maxima of future precipitation has been studied, for durations of between 1 and $32 \mathrm{~d}$. To do this, a process of aggregation has been used to generate rainfall series with durations from 2 to $32 \mathrm{~d}$. In that case $\left\langle I_{d}^{q}\right\rangle$ in Equation (8) is the average value of the $q$-order moment of the rainfall over the six TP stations of Barcelona for a time scale $d$. For all circulation models and scenarios used in the simulation, the results show the existence of a single scale regime throughout the whole range of durations studied (from 1 to $32 \mathrm{~d}$ ). As an example, Figure 7 shows the results obtained for BCM2 and scenario A1B in the last third of the century. From this analysis and the former one performed on the Jard $t$ series, one single scale regime in the time range from $1 \mathrm{~h}$ to $32 \mathrm{~d}$ can be inferred. Considering these scaling properties the expression of the IDF relationship can be expressed as Equation (9).

$$
I(T, d)=f(T) d^{\beta}
$$

Applying Equation (8) for each model, scenario and TP station considered, the exponent of the power function that expresses the dependence on duration $d$ of the IDF curves for the control period and for the future period has been obtained. The average exponent for the control series has resulted $\beta=-0.83$ while for the four scenarios (A1B, A2, B1 and B2) the exponent resulted slightly higher. The scaling exponents obtained for the 

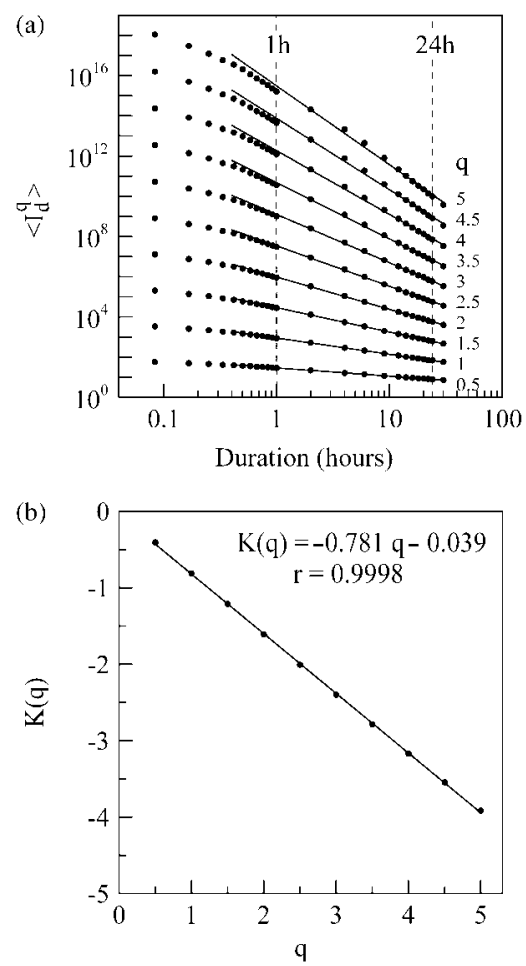

Figure 6. (a) Statistical moments for different values of $q$ of the annual maximum intensity of the Jardí series, as a function of the duration (between $5 \mathrm{~min}$ and $30 \mathrm{~h}$ ). The fitted straight lines indicate scale invariance over the range from $1 \mathrm{~h}$ to $30 \mathrm{~h}$. Their slopes determine the scale function $K(q)$. (b) Linear regression between $K(q)$ and the order $q$ of the moments.
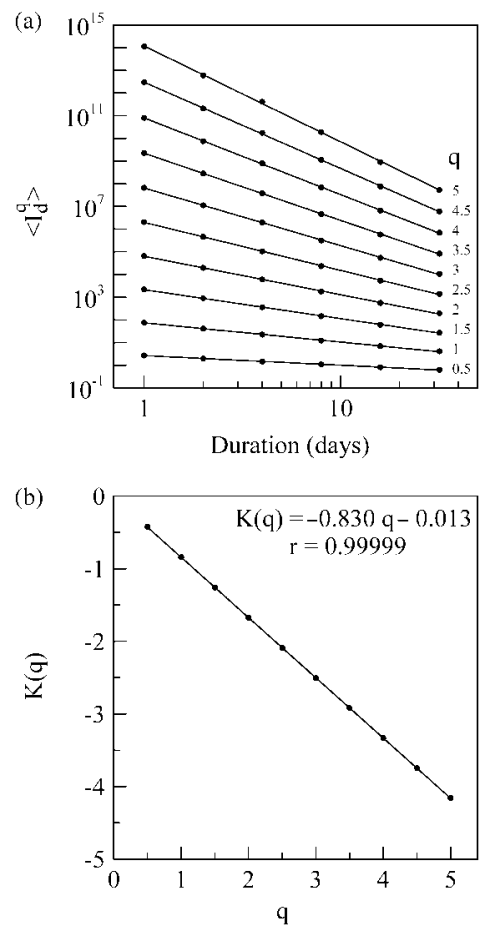

Figure 7. (a) Statistical moments $\left\langle I_{d}^{q}\right\rangle$ of the annual maximum intensity series from $\mathrm{BCM} 2$ under scenario $\mathrm{A} 1 \mathrm{~B}$, as a function of the duration $d$ (between $1 \mathrm{~d}$ and $32 \mathrm{~d}$ ), for several values of $q$. The fitted straight lines indicate scale invariance over the range from $1 \mathrm{~h}$ to $30 \mathrm{~h}$. Their slopes determine the scale function $K(q)$. (b) Linear regression between $K(q)$ and the order $q$ of the moments.
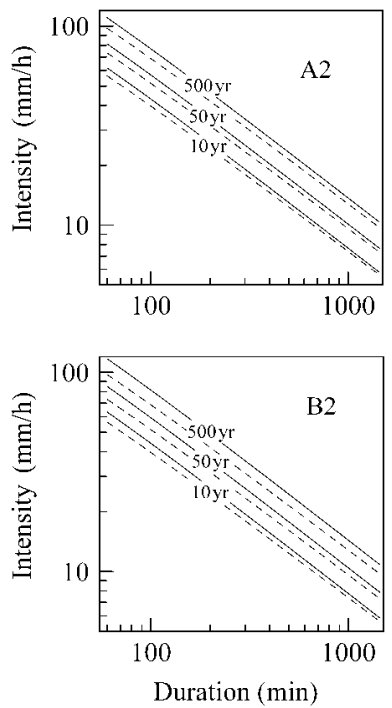

Figure 8. IDF curves estimated for the period 2066-2099 under scenarios A2 and B2 (continuous lines) considering scaling invariance of rainfall, compared to the current IDF (dashed lines).

different models and scenarios in every climate periods (Table III) are very similar to those found by other authors, as Bara et al . (2009) in Slovakia. From Equation (9) the relationship between the daily and the sub-daily intensities for every return period can be easily obtained (Equation 10).

$$
I(T, d)=I(T, 24)\left(\frac{d}{24}\right)^{\beta}
$$

Equation (10) has been applied to obtain future rainfall intensities for durations between 1 and $24 \mathrm{~h}$ and several return periods, i.e. future IDF points under the assumption of scaling invariance of rainfall. Figure 8 shows the generated IDF data for climate change scenarios A2 and B2 compared to the present IDF curves (Equation 6).

The climate change factors corresponding to the estimated hourly intensities have been determined using Equation (5). These factors are consigned in Table IV for every period and every change climate scenario. Figures 9 and 10 show the factors corresponding to the second and last thirds of the century together with their $68 \%$ and $95 \%$ confidence intervals. The climate change factors obtained for all models and scenarios and the three climate periods considered are in most of the cases slightly higher than those calculated considering them invariant with rainfall duration (Table I). The largest differences are obtained for scenarios A2 (9\%) and A1B (8\%) for the period 2033-2065. Table V shows the hourly rainfall intensity for several return periods obtained for all the climate change scenarios and periods considered in this study.

A clear tendency has been found towards increased extreme $1 \mathrm{~h}$-rainfall for all the three thirds of the $21 \mathrm{st}$ century and all scenarios. For the period 2000-2032, the extreme $1 \mathrm{~h}$-rainfall increases with a probability of $95 \%$ under scenario B2. For the period 2033-2065, it increases with a probability of $95 \%$ under scenarios A1B 
Table III. Scaling exponents $(0.3 \%$ error $)$ obtained for every climate period considered.

\begin{tabular}{|c|c|c|c|c|c|c|}
\hline $2000-2032$ & BCM2 & CNCM3 & ECHAM5 & EGMAM & CGCM2 & Mean \\
\hline $\begin{array}{l}\text { Control } \\
\text { A1B } \\
\text { A2 } \\
\text { B1 } \\
\text { B2 }\end{array}$ & $\begin{array}{l}-0.821 \\
-0.846 \\
-0.859 \\
-0.855\end{array}$ & $\begin{array}{l}-0.841 \\
-0.828 \\
-0.835 \\
-0.856\end{array}$ & $\begin{array}{l}-0.838 \\
-0.798 \\
-0.830 \\
-0.821\end{array}$ & $\begin{array}{l}-0.829 \\
-0.855 \\
-0.850 \\
-0.807\end{array}$ & $\begin{array}{l}-0.841 \\
-0.865 \\
-0.855\end{array}$ & $\begin{array}{l}-0.834 \\
-0.832 \\
-0.876 \\
-0.835 \\
-0.855\end{array}$ \\
\hline $\begin{array}{l}2033-2065 \\
\text { CONTROL } \\
\text { A1B } \\
\text { A2 } \\
\text { B1 } \\
\text { B2 }\end{array}$ & $\begin{array}{l}-0.821 \\
-0.863 \\
-0.863 \\
-0.820\end{array}$ & $\begin{array}{l}-0.841 \\
-0.846 \\
-0.870 \\
-0.861\end{array}$ & $\begin{array}{l}-0.838 \\
-0.878 \\
-0.863 \\
-0.842\end{array}$ & $\begin{array}{l}-0.829 \\
-0.829 \\
-0.870 \\
-0.827\end{array}$ & $\begin{array}{l}-0.841 \\
-0.847 \\
-0.825\end{array}$ & $\begin{array}{l}-0.834 \\
-0.854 \\
-0.862 \\
-0.838 \\
-0.825\end{array}$ \\
\hline $\begin{array}{l}2066-2099 \\
\text { Control } \\
\text { A1B } \\
\text { A2 } \\
\text { B1 } \\
\text { B2 }\end{array}$ & $\begin{array}{l}-0.821 \\
-0.830 \\
-0.835 \\
-0.875\end{array}$ & $\begin{array}{l}-0.841 \\
-0.849 \\
-0.873 \\
-0.849\end{array}$ & $\begin{array}{l}-0.838 \\
-0.804 \\
-0.852 \\
-0.848\end{array}$ & $\begin{array}{l}-0.829 \\
-0.827 \\
-0.827 \\
-0.819\end{array}$ & $\begin{array}{l}-0.841 \\
-0.880 \\
-0.858\end{array}$ & $\begin{array}{l}-0.834 \\
-0.828 \\
-0.853 \\
-0.848 \\
-0.858\end{array}$ \\
\hline
\end{tabular}

and A2. For the period 2066-2099, it increases with a probability of $95 \%$ under scenarios A2, B1 and B2. The greatest value of the climate change factor, more than 1.12 for return periods longer than 10 years, has been obtained under scenario B2 in the climate period 2066-2099. Anyway, as commented before, results for scenario B2 are not as significant as the rest due to the only contribution of one climate model to the analysis. For the same climate and return periods, the values of the climate change factor vary between 1.10 and 1.13 under scenario A2, whereas Larsen et al. (2009) found a value of 1.2 for return periods longer than 20 years. In fact, Larsen et al. (2009) concluded that a 1-h precipitation event with a 20-year return at present in Spain will become a 10-year event at the end of the 21 st century. According to our results under A2, at the last third of the century a return period of 11 years will be assigned to a present 20-year hourly rainfall amount. Under A1B, the highest values are reached in the second third of the century, varying from 1.12 to 1.17 for return periods from 10 to 500 years. It is remarkable that these climate factors have resulted greater than in the last third of the century, as found by Gregersen et al. (2011). This result can be related to the greenhouse gas emissions decrease under A1B scenario in the end of the century (IPCC, 2000). Under scenario B1, the highest values are similar in the second and last third, between 1.04 and 1.07 for return periods from 10 to 500 years. Climate change factor values have resulted generally lower for the first third of the century. Average climate factor decrease with increasing returns periods in the same two cases found in Section 3 for extreme daily rainfall.

\section{Conclusions}

A total of 114 simulated daily rainfall series for six TP stations located in the metropolitan area of Barcelona,
84 for the period 2000-2099 and 30 series for the control period 1951-1999, have been analysed in order to investigate the effects of climate change on hydrology in this area. Results show a considerable variation that depends on the general circulation model used and on the TP station that is referred to. Despite this, there is a clear tendency for the expected extreme rainfall to increase. A remarkable result is that extreme daily rainfall will increase with a probability of $95 \%$ under scenarios A2 and B2 in the period 2066-2099.

The average climate change factors calculated from the daily rainfall series increase with increasing return period in almost all the climate scenarios and periods considered. The highest climate change factors, of more than 1.10 for return periods longer than 50 years, have been obtained under scenario B2 in the climate period 2066-2099 (1.14 for 500 years), being around 1.06 under scenarios A2 and A1B. Thus, in the last third of the $21 \mathrm{st}$ century under the climate scenarios A1B, A2 and B2, the expected precipitation with return periods between 10 and 500 years will exceed the current IDF values for Barcelona in percents varying from $3 \%$ to $14 \%$, the greatest always under B2. Anyway, it should be noted that only one climate model contributed to results for scenario B2, whereas a combination of four or five models were considered for the rest of scenarios. Even though percents have resulted generally lower for the first and the second third of the century, under scenarios A1B and B1 the highest values of the climate change factor for return periods longer than 50 years have been reached in the climate period 2033-2065, varying from 1.03 to 1.08 .

Two temporal downscaling methods have been applied to obtain sub-daily rainfall data from the simulated daily rainfall series. First method assumes the invariance of the climate change factor for any time interval shorter than $24 \mathrm{~h}$. The second method is based on the scaling properties of rainfall. A simple scale regime from $1 \mathrm{~h}$ to 
Table IV. Climate change factors for the expected hourly rainfall in the 21 st century with return periods from 1 to 500 years under the four climate change scenarios considered, obtained by downscaling fractal analysis.

\begin{tabular}{|c|c|c|c|c|c|c|c|}
\hline \multirow{2}{*}{$\begin{array}{l}2000-2032 \\
\text { Scenario }\end{array}$} & \multicolumn{7}{|c|}{ Return period (years) } \\
\hline & 1 & 5 & 10 & 20 & 50 & 100 & 500 \\
\hline A1B & 1.01 & 1.02 & 1.02 & 1.02 & 1.02 & 1.03 & 1.03 \\
\hline A2 & 1.04 & 1.03 & 1.03 & 1.03 & 1.02 & 1.02 & 1.02 \\
\hline B1 & 1.05 & 1.04 & 1.04 & 1.04 & 1.03 & 1.03 & 1.03 \\
\hline B2 & 1.03 & 1.06 & 1.07 & 1.08 & 1.08 & 1.09 & 1.10 \\
\hline \multicolumn{8}{|l|}{$2033-2065$} \\
\hline A1B & 1.08 & 1.11 & 1.12 & 1.13 & 1.14 & 1.15 & 1.17 \\
\hline A2 & 1.09 & 1.09 & 1.10 & 1.10 & 1.10 & 1.10 & 1.11 \\
\hline B1 & 1.03 & 1.03 & 1.04 & 1.04 & 1.05 & 1.06 & 1.07 \\
\hline B2 & 0.95 & 0.96 & 0.96 & 0.97 & 0.97 & 0.98 & 0.98 \\
\hline \multicolumn{8}{|l|}{ 2066-2099 } \\
\hline A1B & 1.02 & 1.03 & 1.04 & 1.04 & 1.04 & 1.04 & 1.05 \\
\hline A2 & 1.06 & 1.09 & 1.10 & 1.10 & 1.11 & 1.12 & 1.13 \\
\hline B1 & 1.05 & 1.05 & 1.05 & 1.05 & 1.05 & 1.05 & 1.06 \\
\hline B2 & 1.05 & 1.11 & 1.12 & 1.14 & 1.16 & 1.17 & 1.20 \\
\hline
\end{tabular}
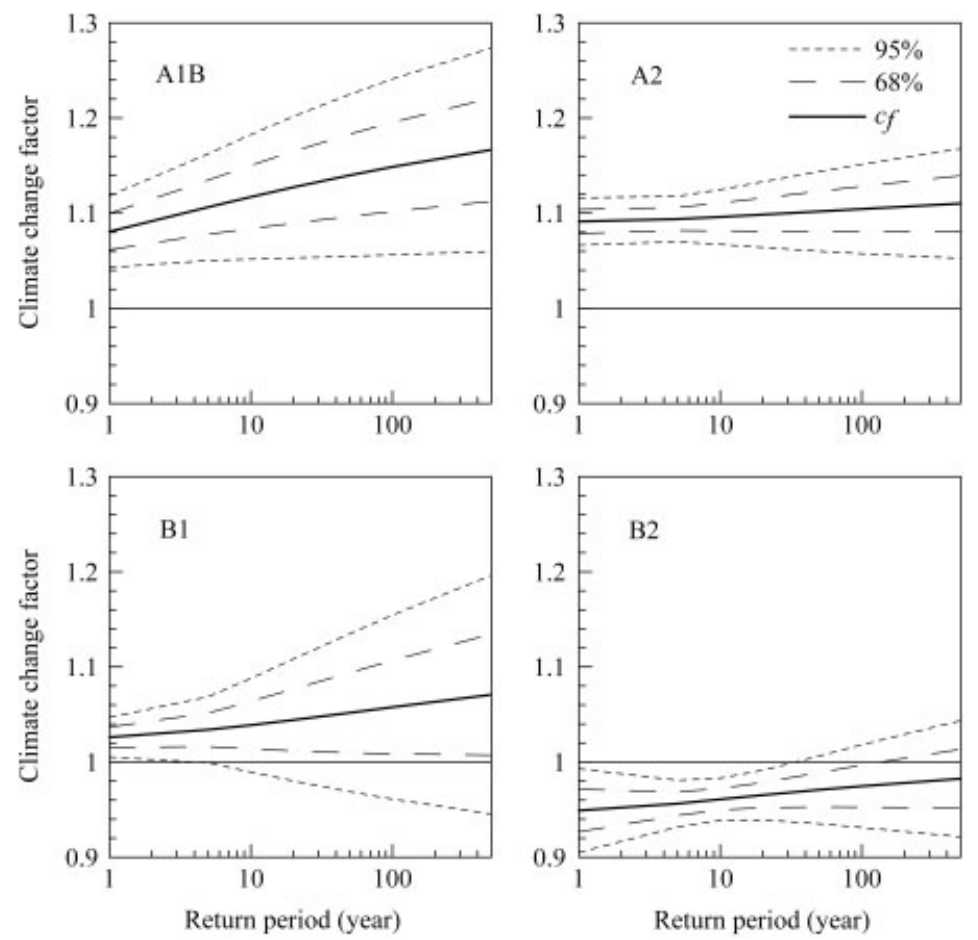

Figure 9. Average climate change factor (continuous) for hourly rainfall, period 2033-2065 and scenarios A1B, A2, B1 and B2. The statistical uncertainty due to sampling variability is shown in the $68 \%$ and $95 \%$ confidence limits (dotted lines).

$32 \mathrm{~d}$ has been observed, with a scaling exponent slightly higher for future series than for control series. Using this scaling method the extreme $1 \mathrm{~h}$-rainfall has been found to increase with a probability of at least $68 \%$ for almost all the climate change scenarios and periods considered. The greatest climate change factor, of more than 1.12 for return periods longer than 10 years, has been obtained under scenario B2 in the climate period 2066-2099. For the same climate and return periods, the values of the climate change factor vary between 1.10 and 1.13 under scenario A2. Under A1B, the highest values have been reached in the second third of the 21st century, varying from 1.12 to 1.17 for return periods from 10 to 500 years. Under scenario B1, the highest values are similar in the second and the last third of the century, between 1.04 and 1.07 for return periods from 10 to 500 years. Climate change factor values have resulted generally lower for the first third of the century. The climate change factors obtained for hourly rainfall are in most of the cases slightly higher than those calculated for daily rainfall. The greatest differences between the climate factors obtained for hourly and daily rainfall 

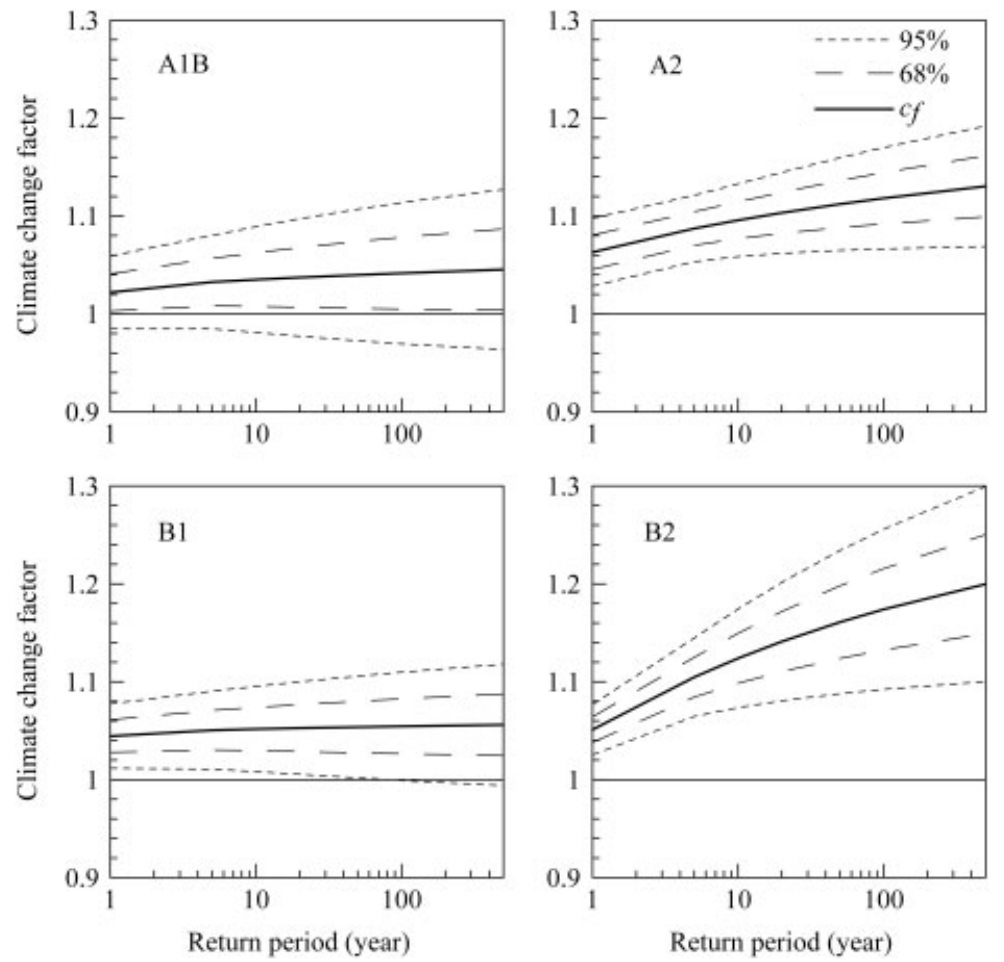

Figure 10. Average climate change factor (continuous) for hourly rainfall, period 2066-2099 and scenarios A1B, A2, B1 and B2. The statistical uncertainty due to sampling variability is shown in the $68 \%$ and $95 \%$ confidence limits (dotted lines).

Table V. 1-h Rainfall intensity ( $\mathrm{mm} / \mathrm{h}$ ) for several return periods and climate scenarios, calculated by downscaling fractal analysis.

\begin{tabular}{|c|c|c|c|c|c|c|c|}
\hline \multirow{2}{*}{$\begin{array}{l}\text { 2000-2032 } \\
\text { Scenario }\end{array}$} & \multicolumn{7}{|c|}{ Return period (years) } \\
\hline & 1 & 5 & 10 & 20 & 50 & 100 & 500 \\
\hline A1B & 32 & 50 & 57 & 65 & 75 & 83 & 100 \\
\hline $\mathrm{A} 2$ & 33 & 51 & 58 & 65 & 75 & 82 & 100 \\
\hline $\mathrm{B} 1$ & 34 & 51 & 59 & 66 & 76 & 83 & 100 \\
\hline $\mathrm{B} 2$ & 33 & 52 & 60 & 68 & 79 & 88 & 107 \\
\hline \multicolumn{8}{|l|}{$2033-2065$} \\
\hline A1B & 35 & 54 & 63 & 72 & 84 & 93 & 114 \\
\hline A2 & 35 & 54 & 62 & 70 & 81 & 89 & 108 \\
\hline B1 & 33 & 51 & 59 & 67 & 77 & 85 & 105 \\
\hline B2 & 30 & 47 & 54 & 61 & 71 & 79 & 96 \\
\hline \multicolumn{8}{|l|}{$2066-2099$} \\
\hline $\mathrm{A} 1 \mathrm{~B}$ & 33 & 51 & 58 & 66 & 76 & 84 & 102 \\
\hline A2 & 34 & 53 & 62 & 70 & 82 & 90 & 110 \\
\hline B1 & 33 & 52 & 59 & 67 & 77 & 85 & 103 \\
\hline B2 & 34 & 54 & 63 & 73 & 85 & 95 & 117 \\
\hline
\end{tabular}

have been found in the second third of the century for scenarios A1B (8\%) and A2 (9\%).

\section{Acknowledgements}

This work was supported by CETaqua and $\mathrm{R}+\mathrm{i}$ Alliance, under project SW0801-phase2, and by the Spanish Ministry of Science and Innovation under Grant CGL200765891-C05-03. The authors are also grateful to Clavegueram de Barcelona S.A. (CLABSA) for providing part of the rain data used in this study.

\section{References}

Arnbjerg-Nielsen K. 2012. Quantification of climate change effects on extreme precipitation used for high resolution hydrologic design. Urban Water Journal 9(2): 57-65. DOI: 10.1080/1573062X.2011.630091

Bara M, Kohnová S, Gaál L, Szolgay J, Hlavčová K. 2009. Estimation of IDF curves of extreme rainfall by simple scaling in Slovakia. Contributions to Geophysics and Geodesy 39(3): 187-206.

Benjoudi H, Hubert P, Schertzer D, Lovejoy S. 1997. Multifractal point of view on rainfall intensity-duration-frequency curve. Comptes rendus de l'Academie des Sciences Paris Earth and Planetary Science 325: $323-326$.

Buonomo E, Jones E, Huntingford C, Hammaford J. 2007. On the robustness of changes in extreme precipitation over Europe from two 
high resolution climate change simulations. The Quarterly Journal of the Royal Meteorological Society 133: 65-81.

Burgueño A, Codina B, Redaño A, Lorente J. 1994. Basic Statistical Characteristics of Hourly Rainfall Amounts in Barcelona. Theoretical and Applied Climatology 49: 175-181.

Burlando P, Rosso R. 1996. Scaling and multiscaling models of depth-duration-frequency curves for storm precipitation. Journal of Hydrology 187: 45-64.

Casas MC, Codina B, Redaño A, Lorente J. 2004. A methodology to classify extreme rainfall events in the western Mediterranean area. Theoretical and Applied Climatology 77: 139-150.

Christensen JH, Christensen OB. 2003. Severe summertime flooding in Europe. Nature 421: 805-806.

Desramaut, N., 2008: Estimation of intensity Duration Frequency Curves for Current and Future Climates, Thesis of Master. Department of Civil Engineering and Applied Mechanics. McGill University, Montreal, Quebec, Canada, http://digitool.library.mcgill.ca/R/?func $=$ dbin-jump-full\&object_id=40816\&current_base=GEN01

Gregersen, I.B., Madsen, H. and Arnbjerg-Nielsen, K., 2011. Estimation of climate factors for future extreme rainfall: Comparing observations and RCM simulations. In Proceedings of the 12th International Conference on Urban Drainage, Porto Alegre, Brazil .

Gupta VK, Waymire E. 1990. Multiscaling properties of spatial rainfall and river flow distributions. Journal of Geophysical Research 95(D3): 1999-2009.

Hertig E, Jacobeit J. 2008. Assessments of Mediterranean precipitation changes for the 21 st century using statistical downscaling techniques. International Journal of Climatology 28: 1025-1045.

Imbert A, Benestad RE. 2005. An improvement of analog model strategy for more reliable local climate change scenarios. Theoretical and Applied Climatology 82: 245-255. DOI: 10.1007/s00704-005-0133-4

IPCC. 2000. Special Report Emission Scenarios. Intergovernmental Panel on Climate Change. Cambridge University Press: Cambridge, UK.

IPCC. 2007. Fourth Assessment Report of the Intergovernmental Panel on Climate Change. University Press: Cambridge, UK.

Koutsoyiannis D, Foufoula-Georgiu E. 1993. A scaling model of storm hyetograph. Water Resources Research 29(7): 2345-2361.

Kruizinga S, Murphy AH. 1983. Use of an analogue procedure to formulate objective probabilistic temperature forecasts in the Netherlands. Monthly Weather Review 111: 2245-2254.

Larsen AN, Gregersen IB, Christensen OB, Linde JJ, Mikkelsen PS. 2009. Potential future increase in extreme one-hour precipitation events over Europe due to climate change. Water Science and Technology 60: 2205-2216.

Martin E, Timbal B, Brun E. 1997. Downscaling of general circulation model outputs simulation of the snow climatology of the French
Alps and sensitivity to climate change. Climate Dynamics 13: $45-56$.

Menabde M, Seed A, Pegram G. 1999. A simple scaling model for extreme rainfall. Water Resources Research 35(1): 335-339.

Nguyen VT, Nguyen TD, Ashkar F. 2002. Regional frequency analysis of extreme rainfalls. Water Science and Technology 45(2): 75-81.

Nhat LM, Tachikawa Y, Sayama T, Takaka K. 2007. A simple scaling characteristic of rainfall in time and space to derive intensity duration frequency relationships. Annual Journal of Hydraulic Engineering 51: $73-78$.

Ntegeka V, Willems P. 2008. Trends and multidecadal oscillations in rainfall extremes, based on a more than 100 years time series of $10 \mathrm{~min}$ rainfall intensities at Uccle, Belgium. Water Resources Research 44: W07402. DOI: 10.1029/2007WR006471

Olsson J, Berggren K, Olofsson M, Viklander M. 2009. Applying climate model precipitation scenarios for urban hydrological assessment: A case study in Kalmar City, Sweden. Atmospheric Research 92: $364-375$.

Pérez, F.F., Boscolo, R., 2010. Clima en España: Pasado, presente y futuro. Informe de Evaluación del Cambio climático Regional. Red Temática CLIVAR-España. http://clivar.iim.csic.es/ files/informe_clivar_final.pdf.

Ribalaygua J, Torres L, Pórtoles J, Monjo R, Gaitán E, Pino MR. 2013. Description and validation of a two-step analogue/regression downscaling method. Theoretical and Applied Climatology 111. DOI: $10.1007 / \mathrm{s} 00704-013-0836-\mathrm{x}$

Wilby, R.L., Charles, S.P., Zorita, E., Timbal, B., Whetton, P., Mearns, L.O., 2004: The guidelines for use of climate scenarios developed from statistical downscaling methods. Supporting material of the Intergovernmental Panel on Climate Change (IPCC), prepared on behalf of Task Group on Data and Scenario Support for Impacts and Climate Analysis (TGICA), Available at http://ipccddc.cru.uea.ac.uk/guidelines/StatDown_Guide.pdf.

Willems P, Vrac M. 2011. Statistical precipitation downscaling for small-scale hydrological impact investigations of climate change. Journal of Hydrology 402: 193-205. DOI: 10.1016/j.jhydrol.2011.02.030

Willems P, Arnbjerg-Nielsen K, Olsson J, Nguyen VTV. 2011. Climate change impact assessment on urban rainfall extremes and urban drainage: Methods and shortcomings. Atmospheric Research . DOI: 10.1016/j.atmosres.2011.04.03003

Yu PS, Yang TC, Lin CS. 2004. Regional rainfall intensity formulas based on scaling property of rainfall. Journal of Hydrology 295(1-4): $108-123$.

Zorita E, von Storch H. 1999. The analog method as a simple statistical downscaling technique: comparison with more complicated methods. Journal of Climate 12: 2474-2489. 